Gazi University
Journal of Science
$\mathrm{http} / /$ dergipark.gov.tr/gujs

\title{
Modelling Wind Energy Potential in Different Regions with Different Methods
}

\author{
Mehmet DAS $^{1, *(D)}$, Ebru K. AKPINAR ${ }^{2}$ (D) Sinan AKPINAR $^{3}$ (D) \\ ${ }^{1}$ Faculty of Engineering and Architecture, Mechanical Engineering Department, Tokat Gaziosmanpaşa University, 60250, Tokat, Turkey \\ ${ }^{2}$ Department of Mechanical Engineering, Firat University, Elazig, 23279, Turkey \\ ${ }^{3}$ Department of Physics, Firat University, Elazig, 23700, Turkey
}

Highlights

- Modeling of wind power density values with machine learning algorithms.

- Wind energy statistical analysis with Weibull cumulative distribution function.

- Generating mathematical equations for wind power distribution.

\section{Article Info}

Received:15 Sep 2020 Accepted:07 Jan 2021

\section{Keywords}

Wind energy Weibull distribution

Decision tree Multilayer perceptron

\begin{abstract}
Processing a lot of data is a very difficult and laborious task. In order to save time and ease the process, computational intelligence method is a very practical method for data processing. In the present study, the potential of wind energy in different regions of Turkey based on the hourly wind speed data in the years 2008-2017 were analysed statistically. Wind power density values have been examined mathematically and statistically and modelled using artificial intelligence methods. During the statistical analysis, maximum wind speed, average wind speed, wind power density, and standard deviation of wind speed have been determined. The cumulative Weibull function was used to determine wind power density and wind speed distribution on an annual basis using hourly wind speed data. Predictive models have been created by using machine learning algorithms which are computational intelligence method for the obtained wind power density values. Decision tree (DT) algorithm and multilayer perceptron (MLP) algorithm have been chosen as machine learning algorithms. Four different error analyses have been performed for DT and MLP estimates. In the machine algorithms used to estimate wind power values, the DT algorithm performed approximately $35 \%$ more accurate than the MLP algorithm. As a result, wind power densities for certain regions have been determined by using both mathematical model and computational intelligence methods.
\end{abstract}

\section{INTRODUCTION}

Energy produced from fossil resources such as coal, oil and natural gas is the most important factor that determines the development level of countries and the daily needs of people as well as the industry [1]. However, fossil fuels, which are about to run out, are becoming more expensive and their environmental damage is increasing. Due to the negative effects of fossil fuels, interest in renewable energy sources, which are clean and cheap energy sources, is increasing day by day [2]. Wind energy, which has an important place among renewable energy resources, is an alternative type of energy which shows rapid development of electricity generation by approximately 80 countries in the world. Europe achieved a record year by producing $16.8 \mathrm{GW}$ of wind power in 2020 (Figure 1). Wind energy with a total net installed power of 168.7 GW continues to rank 2nd in the energy production capacity in Europe [3].

Various researches have been conducted by the International Energy Agency (IEA) in order to determine the world's wind energy potential. In these surveys, the world technical wind potential is calculated as $53000 \mathrm{TWh} /$ year, based on the predicted use of $4 \%$ of the areas with wind capacity above $5.1 \mathrm{~m} / \mathrm{s}$ with the application of social constraints. [4]. Determining the wind power potential of an area is very important 
for wind energy use. Wind energy potential can be determined using various programs as well as statistically.

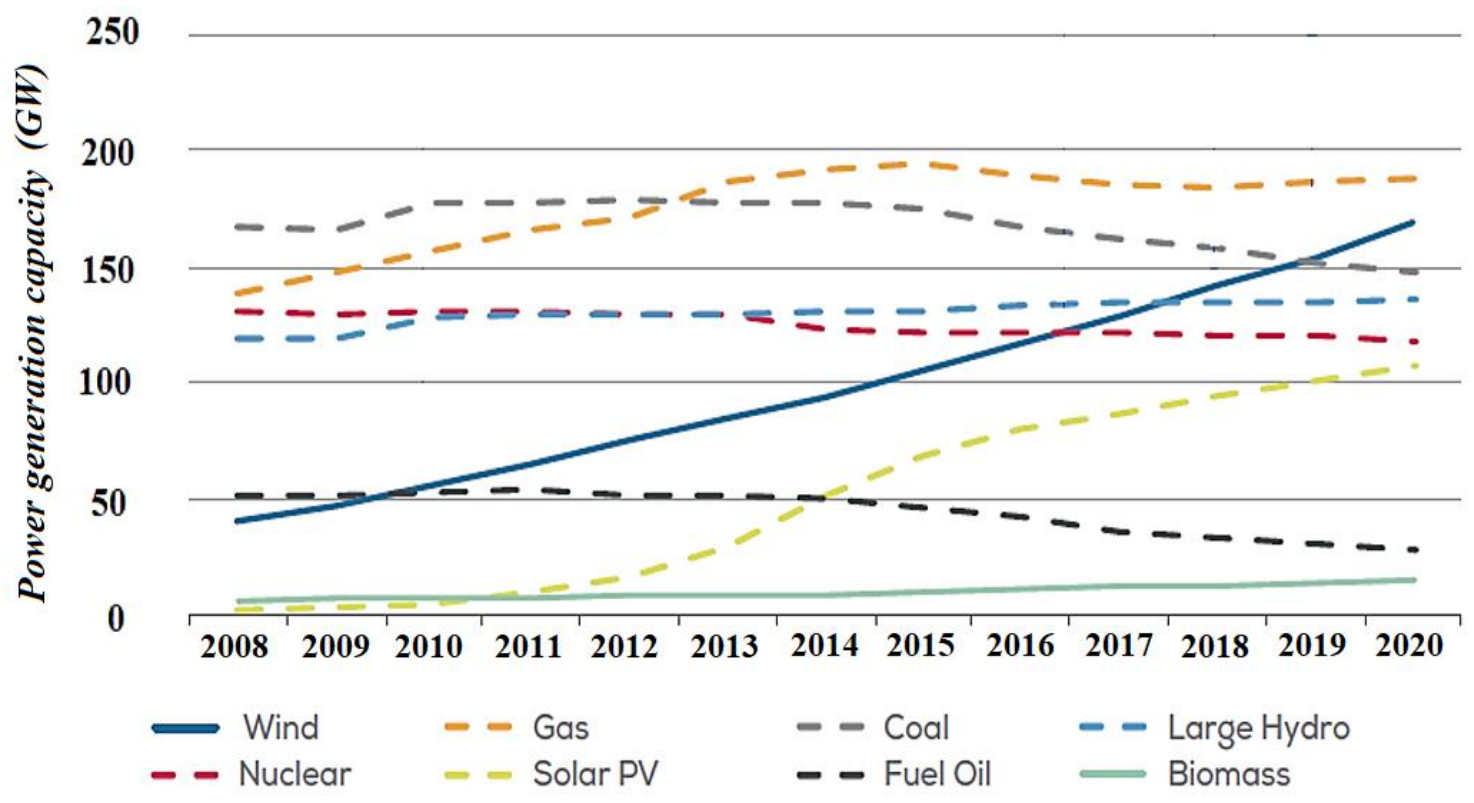

Figure 1. Total power generation capacity in the Europe 2008-2020

A lot of statistical distributions are used for predicting regional wind regimes. In the studies done in the literature, the wind speed is shown by using different distributions such as frequency distribution Gamma, $\log$ normal, Rayleigh. However, in recent years, the two-parameter Weibull distribution and the oneparameter Rayleigh distribution have been used to represent the wind distribution of many regions of the world. The reason for using these methods is that they fit very well into the wind distribution, have a flexible structure and their parameters are easy to determine [5]. Specifically, many data processing studies show that wind speed data can be obtained by Weibull distribution [6-8]. For wind parameters calculated by Weibull distribution, many wind data are used. Various error analyses $\left(\mathrm{R}^{2}, \mathrm{RMSE}, \chi^{2}\right)$ have been made to determine the error rate of this distribution [9-11].

There are many wind energy potential determination studies in the literature using the Weibull distribution function. Thus, the results of the Weibull function were determined and compared with the results obtained by artificial intelligence methods. Some of these studies are included in the sentences below. Shu et al. [12] statistically analysed wind energy potential in the coastal areas surrounding Hong Kong, based on six-year (2005-2010) wind observations from three meteorological stations in the Hong Kong region. Offshore wind energy uses the Weibull distribution function to facilitate the assessment of the potential. Usta [13] has developed an innovative method PWMBP (Probability Weighted Moments based on power density method) as an alternative to the Weibull distribution used for evaluating the wind energy potential. Mohammadi et al. [14] used the Weibull distribution function to calculate wind energy power density at four different stations in Alberta, Canada. They used wind data on both daily and monthly scales to provide a more precise analysis in their calculations.

The Weibull distribution function parameters which are used for wind velocity values are estimated by various computational intelligence methods in the literature. Ramirez and Carta [15] used hourly average wind speed data recorded at an air station in the Canary Archipelago to explain the parameters and errors of the Weibull wind speed probability density distribution. They also suggested that the uncertainties calculated for commonly used wind energy statistics functions were not determinative and therefore, independent wind speed data samples should be used in their estimations. They performed a predictive model with an average standard error of 0.3. Akdag and Dinler [16] estimated the Weibull distribution parameters used to express the wind velocity frequency distribution by the power density (PD) method. 
They stated that it was very easy to estimate the Weibull parameters if power density and average wind speed were present. They compared the PD method with the most commonly used graphics, maximum likelihood and moment methods in the literature. As a result, they performed a predictive model with a power density error of 4. Yu et al. [17] proposed a novel framework for wind speed estimation. Using wavelet transforms, they divide the history of wind speed into several sub-series. They predicted low frequency sub-series using repetitive neural networks with machine learning methods. As a result, they showed that the predictions obtained with the new framework were correct. They obtained a predictive model with an average RMSE analysis result of 0.8 .

This manuscript consists of introduction, analysis, results and discussion and conclusion sections. Weibull cumulative function and machine learning algorithms (DT and MLP) are included in the analysis section. In the section of results and discussion, the results of wind energy values obtained by different methods are given and compared with the studies in the literature. In the conclusion part, the method that best models wind energy value is mentioned.

In this work, velocity and energy distributions were calculated with many wind data by using Weibull cumulative function. To make these calculations more practical, prediction models have been created using some machine learning algorithms. The aim of this study is to use Weibull distribution to determine wind energy potential of Adiyaman - İskenderun provinces and to produce predictive models for wind energy density by using DT and MLP algorithms. Wind speed data for the years 2008-2017 were used for the models. The data of wind speed between the years 2008-2017 were taken from Turkey General Directorate of Meteorology. Relative absolute error (RAE), root mean square error (RMSE), mean absolute error (MAE), and root relative square error (RRSE) analyses were performed to determinate the performance of the obtained predictive models. Among the models for wind energy potential, the best model was made with DT according to the results of error analysis.

\section{ANALYSIS}

\subsection{Analysis of Wind Speed Data}

Data analysis is performed by obtaining the frequency distributions of wind speed data taken from a certain height from wind observation stations. With this frequency distribution, it is possible to determine which wind speed values are frequently observed. When selecting wind turbines, these types of distributions are utilized. The statistical standard deviation value of the wind speed data should be between $0 \mathrm{~m} / \mathrm{s}$ and $3 \mathrm{~m} / \mathrm{s}$. The fact that the standard deviation in any area is small means that the wind regime in that area is extremely regular [18].

There are many distributions used to determine the distribution of wind speed. The Rayleigh distributions and Weibull are the most widely used distributions [18]. The general expression of the two parameter the Weibull probability density function for wind speed is as in Equation (1)

$$
f_{w}(v)=\left(\frac{k}{c}\right)\left(\frac{v}{c}\right)^{k-1} \exp \left(-\left(\frac{v}{c}\right)^{k}\right) .
$$

The expression $\mathrm{c}(\mathrm{m} / \mathrm{s})$, which has a reference value in wind speed data, is used as the scale parameter in the Weibull distribution. In the Equation (1), $\mathrm{k}$ is Weibull shape parameter, $f_{w}(v)$ is the weibull probability density function. The Weibull cumulative distribution $\left(F_{w}(v)\right)$ function is calculated by Equation (2)

$$
F_{w}(v)=1-\exp \left(-\left(\frac{v}{c}\right) k\right) \text {. }
$$

The Weibull cumulative distribution function is used to express the probability that the wind speed is less than or equal to a certain $v$ value. The statistical standard deviation value of the wind speed values are calculated using Equations (3) and (4), respectively. In Equation (3), $\Gamma$ is Gamma function and $v_{m}$ is average wind speed. In Equation (4), $\sigma$ is standard deviation value. 


$$
\begin{aligned}
& v_{m}=c \Gamma\left(1+\frac{1}{k}\right) \\
& \sigma=\sqrt{c^{2}\left[\Gamma\left(1+\frac{2}{\mathrm{k}}\right)-\Gamma^{2}\left(1+\frac{1}{\mathrm{k}}\right)\right]} .
\end{aligned}
$$

Using the Weibull distribution function, the wind speed with the largest frequency is calculated from Equation (5) [19]

$$
V_{\bmod }=c\left(1-\frac{1}{k}\right) 1 / k
$$

The maximum wind speed is calculated with the help of Equation (6) [20]

$$
V_{\max E}=c\left(\frac{k+2}{k}\right) 1 / k \text {. }
$$

The mean power density for the Weibull distribution is given by Equation (7) as follows [20]

$$
P_{w}=\frac{1}{2} \rho c^{3} \Gamma\left(1+\frac{3}{k}\right) \text {. }
$$

In Equations (5)-(7), $V_{\bmod }$ is the wind speed with the highest frequency $(\mathrm{m} / \mathrm{s}), V_{\max }$ is maximum wind speed $(\mathrm{m} / \mathrm{s})$ and $\mathrm{P}_{\mathrm{w}}$ is Weibull function average power density $\left(\mathrm{W} / \mathrm{m}^{2}\right)$ respectively.

\subsection{Machine Learning Algorithms}

Machine learning is a method of building general algorithms that can give you detailed information about a particular dataset without having to write code [21]. We can divide the machine learning algorithms used in various models into groups: unsupervised and supervised learning. In the present work, two machine learning algorithms (decision tree and multilayer perceptron) were used to model wind energy potential.

\subsection{Multilayer Perceptron}

Artificial neural networks are computer programs that perform basic learning functions in the human brain. Learning process is performed by using examples. Artificial neural network which proposes a different method from the known calculation techniques; It is a system that can adapt to its environment, adapt, work with incomplete data, decide in case of uncertainty and has fault tolerance, and can be applied successfully in almost all areas of life [22].

Basic assumptions in artificial neural network models: [23]

- Information coming to the artificial neural network system is processed through units called Neuron.

- The transmission of incoming signals is carried out by means of connections between neurons.

- Each connection has a certain weight. In many ANNs, the link weights are multiplied by the transmitted signals.

- While the weighted sums of the incoming signals through the neurons form the net input, the transfer function, usually a nonlinear function, is applied to the incoming signals to determine the neuron output signal.

Multi-Layer Sensors (MLP) emerged as a result of efforts to solve the XOR Problem. This model, developed by Rumelhart et al., Is also called 'Back Propogation Model' or 'Error Spreading Model' because it spreads the error to the network. MLP is widely used especially in modeling for estimation and classification. The structure of Multilayer Networks is as follows [24]. 
In the MLP algorithm, the network structure consists of six input parameters and one output parameter. Average wind speed $\left(\mathrm{V}_{\mathrm{m}}\right)$, Weibull shape parameter $(\mathrm{k})$, Weibull scale parameter $(\mathrm{c})$, standard deviation $(\sigma)$, maximum frequency $\left(\mathrm{V}_{\text {mod }}\right)$ wind speed and maximum wind speed $\left(\mathrm{V}_{\max }\right)$ values were used as input parameters. $\mathrm{P}_{\mathrm{w}}$ was used as the output parameter. In Figure 2, the network structure that MLP algorithm uses to model wind energy distribution is given. MATLAB 2018b software was used to model wind energy distribution values with MLP. The information set were consisted of 720 input data and 120 output data. 588 data were used for network training in MLP modelling. The parameters and structure of the network model used by the MLP algorithm used to estimate the average wind energy density values of Weibull function are shown in Table 1.

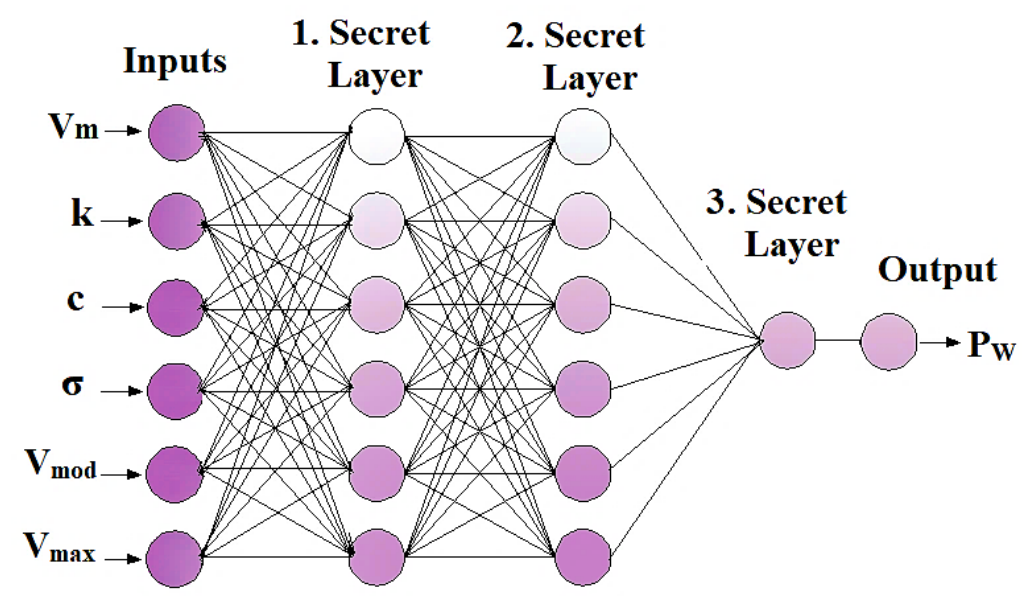

Figure 2. Multilayer perceptron's network structure

Table 1. Multilayer perceptron's network and parameters

\begin{tabular}{ll}
\hline Secret Layer & 3 \\
Neurons in Layers & $6-6-6-1-1$ \\
Weight Values & Random \\
Activation Func. & Tansig \\
Transfer Func. & Tangent Sigmoid Transfer \\
Learning Func. & Feed-Forward Backpropagation \\
\hline
\end{tabular}

\subsection{Decision Tree}

DT is a predictive technique that looks like a tree. DT is rules extraction algorithms. These algorithms can be derived from a data set in a tree structure (IF-THEN), which can be easily understood by users [25]. Therefore, DT are defined as controlled methods. Many algorithms have been developed to create DT. ID3, C4.5, C5.0, "Classification and Regression Trees CAR (CART) and M5 are the most known algorithms [26]. The extended M5P algorithm, known as the M5P algorithm, consists of four parts. The first part consists of the root, the second part consists of the inner root, the third part consists of branches and the last part leaves. In the construction of the tree, the data is processed until it reaches the leaves. The standard deviation reduction (SDR) factor is used to reduce the error rate in data processing (Equation 8) [27]

$S D R=s d(S)-\sum_{i} \frac{S_{i}}{|S|} \times s d\left(S_{i}\right)$

$S$ value refers to the set of data records that reach the node, $S_{i}$ value refers to clusters resulting from dividing the node by a given property, and sd value refers to standard deviation [28]. The basic tree structure formed by a decision tree algorithm consists of three main parts called root, branches and leaves, as shown in Figure 3. 


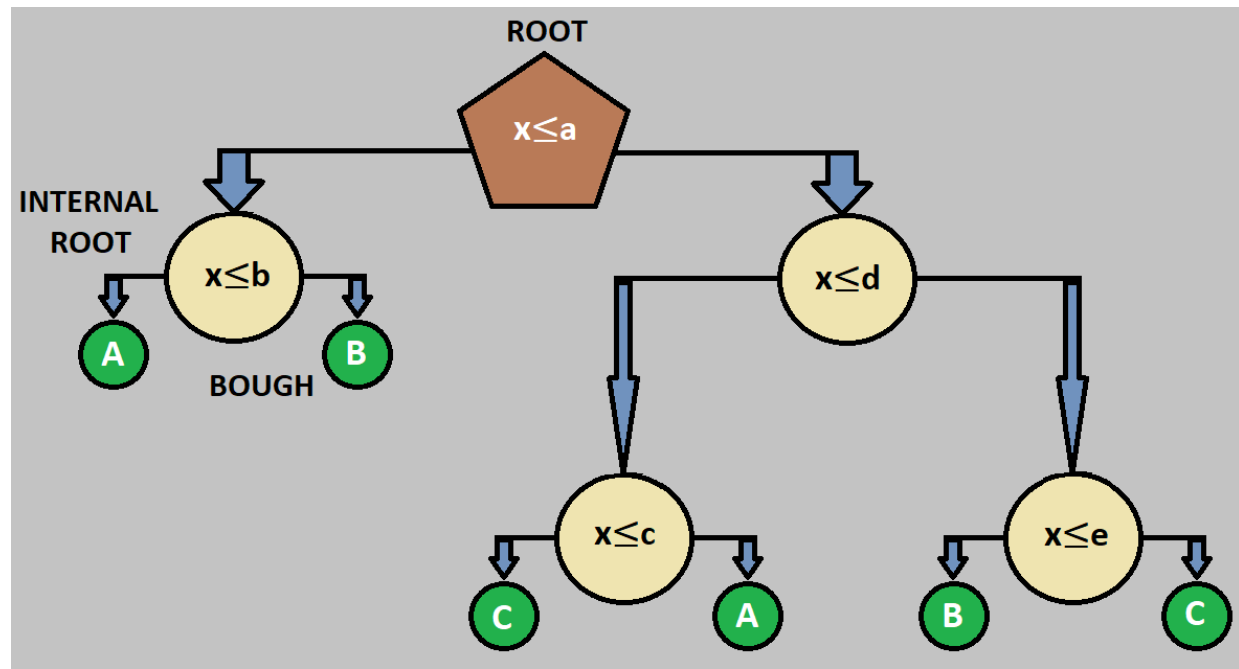

Figure 3. Sample DT structure consisting of various space and classes

As seen in Figure 3, there are three classes and four different attribute values belonging to these classes in DT structure. In figure xi property values, $a, b, c, d$ and e values represent the tree's branch structure and threshold values for class A, B, and C labels [29]. The DT method used the M5P algorithm to estimate wind power values.

In this study, DT and MLP algorithms were used for predicting $\mathrm{P}_{\mathrm{w}}$ values according to years. MAE, RMSE, RAE and RRSE analyses were performed to determine the validity of the obtained model. Error analysis is shown in Table 2.

Table 2. Error analysis, formulas and parameters in wind power density modelling

\begin{tabular}{|c|c|c|c|}
\hline Error Anal. & Equation and Eq. Number & & Parameters \\
\hline MAE & $\frac{\left|P_{1}-A_{1}\right|+\ldots . .+\left|P_{n}-A_{n}\right|}{n}$ & (9) & $\begin{array}{l}\text { P: Prediction Data } \\
\text { A: Real Data } \\
\text { n: Total Data Number }\end{array}$ \\
\hline RMSE & $\sqrt{\frac{\left(\mathrm{P}_{1}-\mathrm{A}_{1}\right)^{2}+\ldots . .+\left(\mathrm{P}_{\mathrm{n}}-\mathrm{A}_{\mathrm{n}}\right)^{2}}{\mathrm{n}}}$ & (10) & $\begin{array}{l}\text { P: Prediction Data } \\
\text { A: Real Data } \\
\text { n: Total Data Number }\end{array}$ \\
\hline RAE & $\frac{\left|\mathrm{P}_{1}-\mathrm{A}_{1}\right|+\ldots . .+\left|\mathrm{P}_{\mathrm{n}}-\mathrm{A}_{\mathrm{n}}\right|}{\left|\mathrm{A}_{1}-\mathrm{A}^{\prime}\right|+\ldots . .+\left|\mathrm{A}_{n}-\mathrm{A}^{\prime}\right|}$ & (11) & $\begin{array}{l}\text { P: Prediction Data } \\
\text { A: Real Data } \\
\text { A': Actual Data Average }\end{array}$ \\
\hline RRSE & $\sqrt{\frac{\left(\mathrm{P}_{1}-\mathrm{A}_{1}\right)^{2}+\ldots . .+\left(\mathrm{P}_{\mathrm{n}}-\mathrm{A}_{\mathrm{n}}\right)^{2}}{\left(\left|\mathrm{~A}_{1}-\mathrm{A}^{\prime}\right|\right)^{2}+\ldots . .+\left(\mathrm{A}_{n}-\mathrm{A}^{\prime}\right)^{2}}}$ & (12) & $\begin{array}{l}\text { P: Prediction Data } \\
\text { A: Real Data } \\
\text { A': Actual Data Average. }\end{array}$ \\
\hline
\end{tabular}

MATLAB 2018b software is used for the DT and the MLP algorithms. In the DT and the MLP 720 input data and 120 output data are used for the predictive model. The data were used in machine algorithms according to Ten-Cross validation method. Cross-validation is a model validation technique that tests how a statistical analysis performed on an independent dataset will result. Its main use is to examine the accuracy of a predictive system in practice [30,31].

\section{RESULTS AND DISCUSSION}

In the present study, the wind energy of Adiyaman and İskenderun is analysed statistically based on the wind speed data measured hourly in 2008 - 2017. The hourly wind data for the years 2008 and 2017 were obtained from the General Directorate of Meteorology. The Weibull distribution was used to investigate the wind energy potential of the selected entities. The values of the air intensities calculated according to the location, elevation, and altitude of the examined illusions are given in Table 3 [32]. 
Table 3. The altitude and air density values of Adiyaman and Iskenderun

\begin{tabular}{|c|c|c|c|}
\hline Provinces & Latitude - Longitude & Altitude (m) & $\underset{\left(\mathrm{kg} / \mathrm{m}^{3}\right)}{\text { Air Density }}$ \\
\hline $\begin{array}{l}\text { Adiyaman } \\
\text { Iskenderun }\end{array}$ & $\begin{array}{llllll}38^{\circ} & 17^{\prime} & \mathrm{N} & -37^{\circ} & 46^{\prime} & \mathrm{E}\end{array}$ & 669 & $\begin{array}{ll}1.145 & 1,213\end{array}$ \\
\hline
\end{tabular}

The Weibull cumulative distribution function is used for wind power intensities of Adiyaman and Iskenderun. The Weibull distribution of the deflection parameters are provided for the wind power potential is given in Tables $4-5$ below.

Table 4. Weibull function parameters for Adiyaman

\begin{tabular}{llllllll} 
Year & $\mathbf{k}$ & $\mathbf{c}(\mathbf{m} / \mathbf{s})$ & $\mathbf{V}_{\mathbf{m}}(\mathbf{m} / \mathbf{s})$ & $\boldsymbol{\sigma}(\mathbf{m} / \mathbf{s})$ & $\mathbf{V}_{\mathbf{m o d}}(\mathbf{m} / \mathbf{s})$ & $\mathbf{V}_{\mathbf{m a x}}(\mathbf{m} / \mathbf{s})$ & $\mathbf{P}_{\mathbf{w}}\left(\mathbf{W} / \mathbf{m}^{2}\right)$ \\
\hline $\mathbf{2 0 0 8}$ & 1.9807 & 2.1202 & 1.8793 & 0.9909 & 1.4867 & 3.0159 & 7.2455 \\
$\mathbf{2 0 0 9}$ & 1.8653 & 2.0378 & 1.8095 & 1.0072 & 1.3500 & 3.0117 & 6.8904 \\
$\mathbf{2 0 1 0}$ & 1.8148 & 2.0198 & 1.7955 & 1.0246 & 1.2992 & 3.0416 & 6.9432 \\
$\mathbf{2 0 1 1}$ & 1.8197 & 1.9977 & 1.7756 & 1.0107 & 1.2888 & 3.0026 & 6.6946 \\
$\mathbf{2 0 1 2}$ & 2.1428 & 2.0749 & 1.8376 & 0.9028 & 1.5473 & 2.8224 & 6.2806 \\
$\mathbf{2 0 1 3}$ & 1.8700 & 1.9130 & 1.6984 & 0.9433 & 1.2705 & 2.8225 & 5.6830 \\
$\mathbf{2 0 1 4}$ & 2.1705 & 1.9573 & 1.7334 & 0.8419 & 1.4726 & 2.6444 & 5.2113 \\
$\mathbf{2 0 1 5}$ & 1.9591 & 1.9008 & 1.6852 & 0.8974 & 1.3201 & 2.7220 & 5.2836 \\
$\mathbf{2 0 1 6}$ & 1.9780 & 1.8481 & 1.6382 & 0.8649 & 1.2944 & 2.6311 & 4.8057 \\
$\mathbf{2 0 1 7}$ & 2.1826 & 1.5819 & 1.4009 & 0.6770 & 1.1946 & 2.1310 & 2.7377 \\
\hline
\end{tabular}

Table 5. Weibull function parameters for Iskenderun

\begin{tabular}{llllllll}
\hline Year & $\mathbf{k}$ & $\mathbf{c}(\mathbf{m} / \mathbf{s})$ & $\mathbf{V}_{\mathbf{m}}(\mathbf{m} / \mathbf{s})$ & $\boldsymbol{\sigma}(\mathbf{m} / \mathbf{s})$ & $\mathbf{V}_{\mathbf{m o d}}(\mathbf{m} / \mathbf{s})$ & $\mathbf{V}_{\max }(\mathbf{m} / \mathbf{s})$ & $\mathbf{P}_{\mathbf{w}}\left(\mathbf{W} / \mathbf{m}^{\mathbf{2}}\right)$ \\
\hline $\mathbf{2 0 0 8}$ & 1,8460 & 2,9917 & 2,6575 & 1,4932 & 1,9605 & 4,4524 & 23,877 \\
$\mathbf{2 0 0 9}$ & 1,8232 & 2,9147 & 2,5905 & 1,4720 & 1,8845 & 4,3751 & 22,4286 \\
$\mathbf{2 0 1 0}$ & 1,7104 & 2,7713 & 2,4717 & 1,4882 & 1,6581 & 4,3583 & 21,0183 \\
$\mathbf{2 0 1 1}$ & 1,8784 & 2,7199 & 2,4145 & 1,3355 & 1,8148 & 4,0010 & 17,5662 \\
$\mathbf{2 0 1 2}$ & 1,8771 & 2,7485 & 2,4399 & 1,3505 & 1,8325 & 4,0451 & 18,1425 \\
$\mathbf{2 0 1 3}$ & 1,8401 & 2,7430 & 2,4369 & 1,3733 & 1,7914 & 4,0913 & 18,4778 \\
$\mathbf{2 0 1 4}$ & 1,6369 & 2,3674 & 2,1184 & 1,3276 & 1,3299 & 3,8556 & 13,9974 \\
$\mathbf{2 0 1 5}$ & 1,5430 & 2,3002 & 2,0698 & 1,3692 & 1,1690 & 3,9420 & 14,1570 \\
$\mathbf{2 0 1 6}$ & 1,6654 & 2,6589 & 2,3759 & 1,4657 & 1,5327 & 4,2699 & 19,3091 \\
$\mathbf{2 0 1 7}$ & 1,6378 & 2,7814 & 2,4887 & 1,5589 & 1,5638 & 2,5277 & 22,6792 \\
\hline
\end{tabular}

In Table 4, the Weibull distribution parameters are given according to years. $\mathrm{V}_{\max }$ values in the Weibull distribution are between 2.13 and $3.04 \mathrm{~m} / \mathrm{s}$ and $\mathrm{P}_{\mathrm{w}}$ values are between 2.74 and $7.25 \mathrm{~W} / \mathrm{m}^{2}$.

In Table 5, $\mathrm{V}_{\max }$ values in the Weibull distribution are between 2.52 and $4.45 \mathrm{~m} / \mathrm{s}$ and $\mathrm{P}_{\mathrm{w}}$ values are between $13.99-23.88 \mathrm{~W} / \mathrm{m}^{2}$.

For the Adiyaman and İskenderun in Figures 4 and 5 below, the variation of wind power intensity and average wind speed according to the Weibull distribution is shown according to years. 


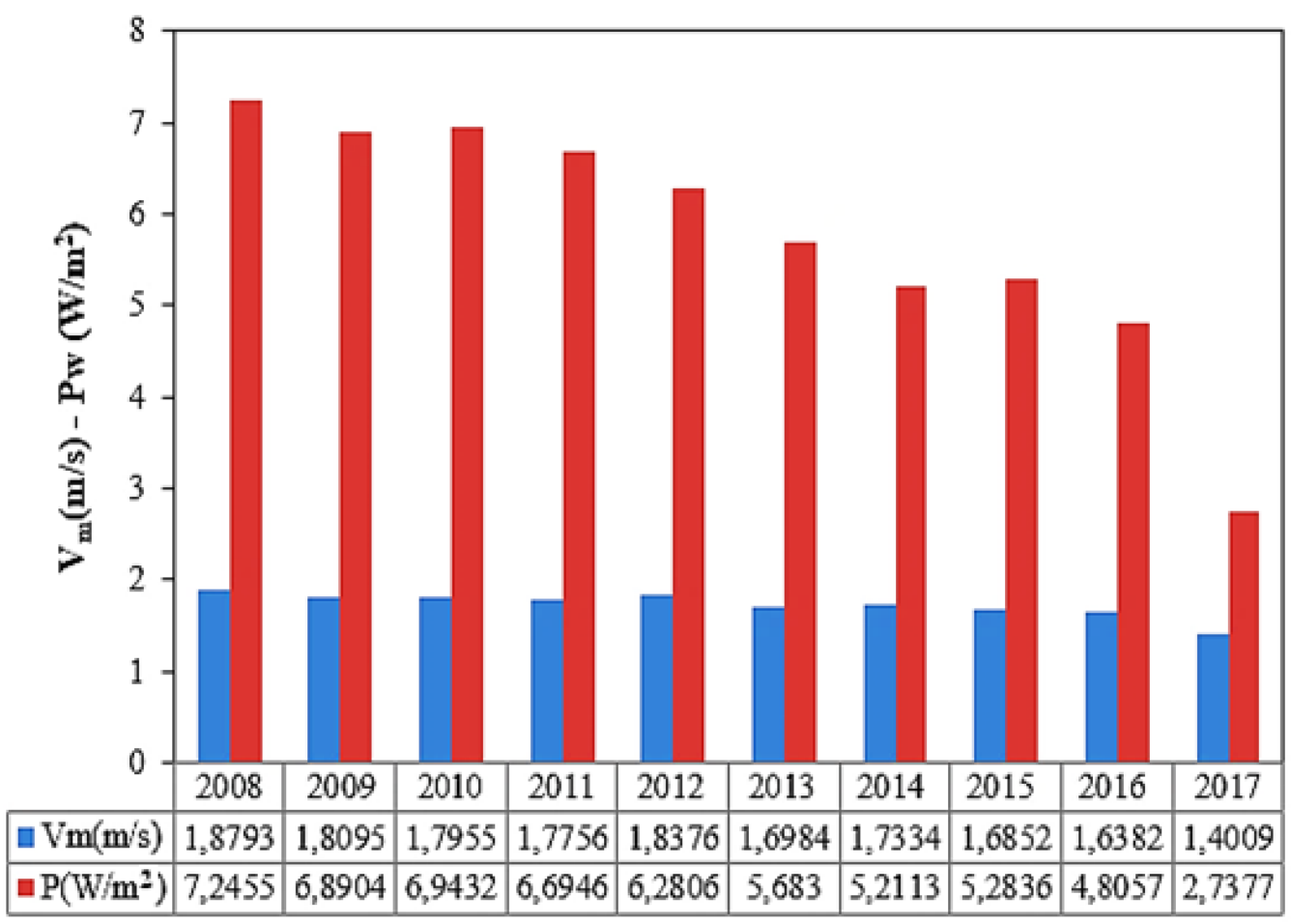

Figure 4. Average wind speeds and wind energy densities of Adlyaman province (2008-2017)

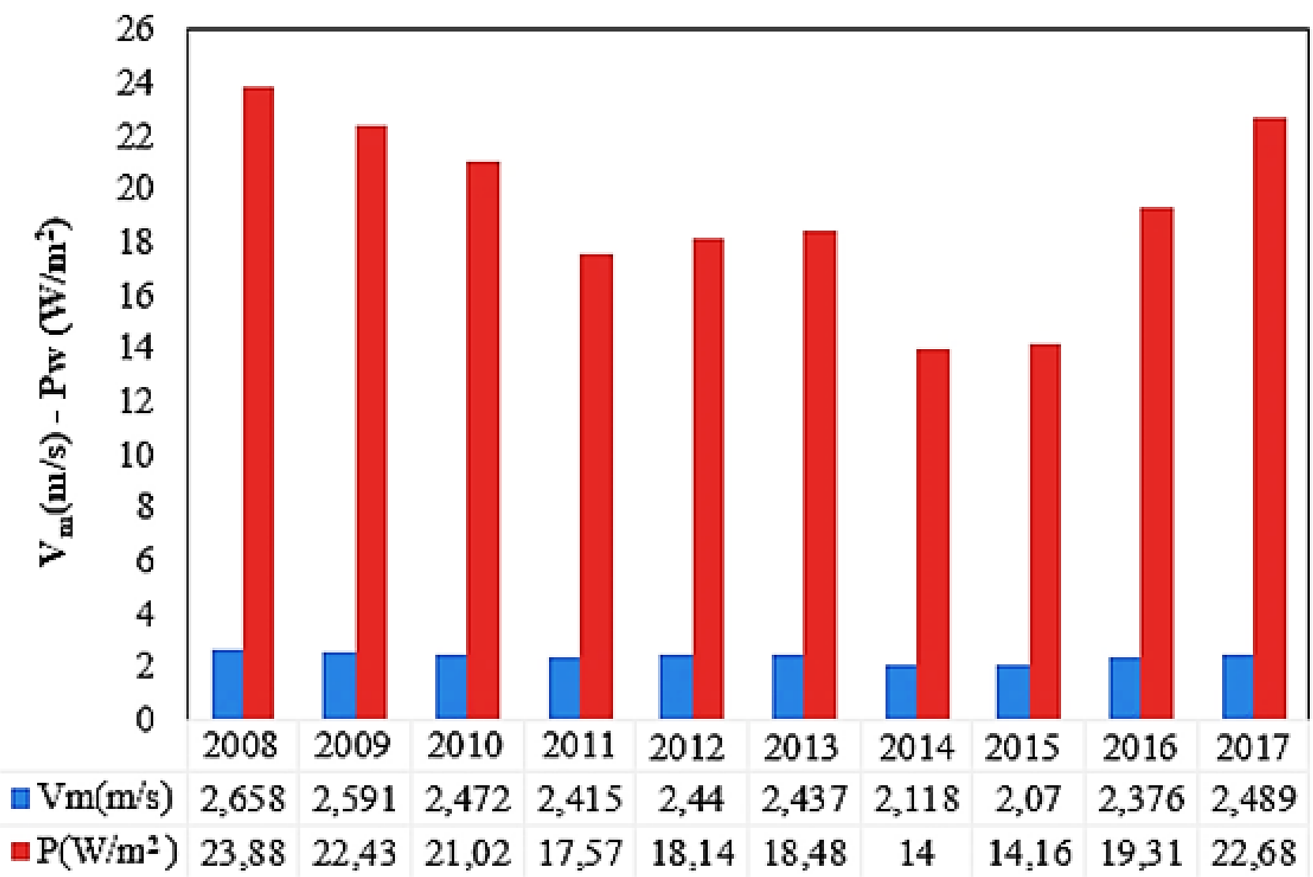

Figure 5. Average wind speeds and wind energy densities of Iskenderun province (2008-2017)

According to Figure 4, the highest $\mathrm{P}_{\mathrm{w}}$ according to the Weibull distribution for Adiyaman is $7.24 \mathrm{~W} / \mathrm{m}^{2}$ in 2008 and the lowest $\mathrm{P}_{\mathrm{w}}$ value is $5.21 \mathrm{~W} / \mathrm{m}^{2}$ in 2014. Figure 5 shows that the highest $\mathrm{P}_{\mathrm{w}}$ value according to the Weibull distribution for İskenderun is $23.88 \mathrm{~W} / \mathrm{m}^{2}$ in 2008 and the lowest $\mathrm{P}_{\mathrm{w}}$ value is $14 \mathrm{~W} / \mathrm{m}^{2}$ in 2014 . The change in mean wind speeds calculated according to the ten-year period for the provinces of Adiyaman and İskenderun is shown in Figures 6-7 for each year. 


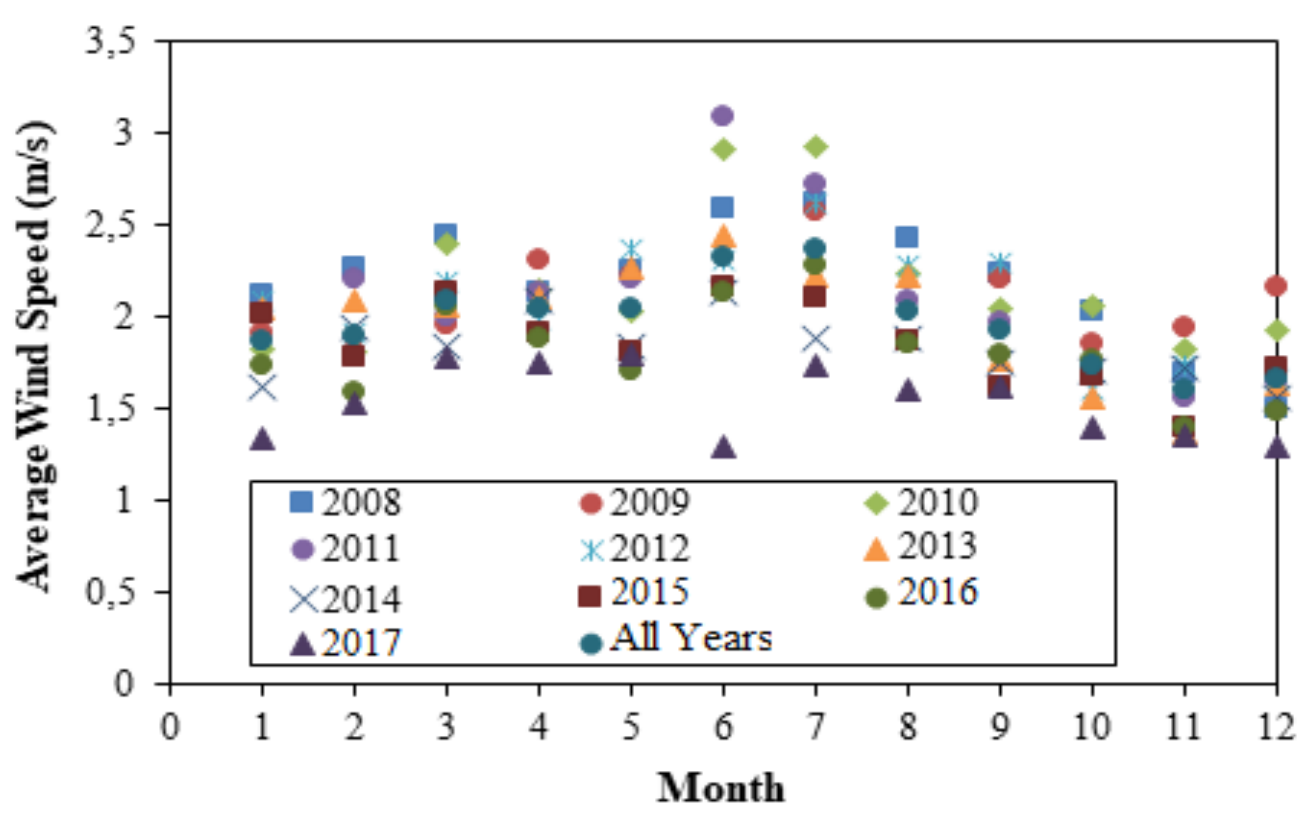

Figure 6. Exchange by months the average wind speed for Adlyaman province

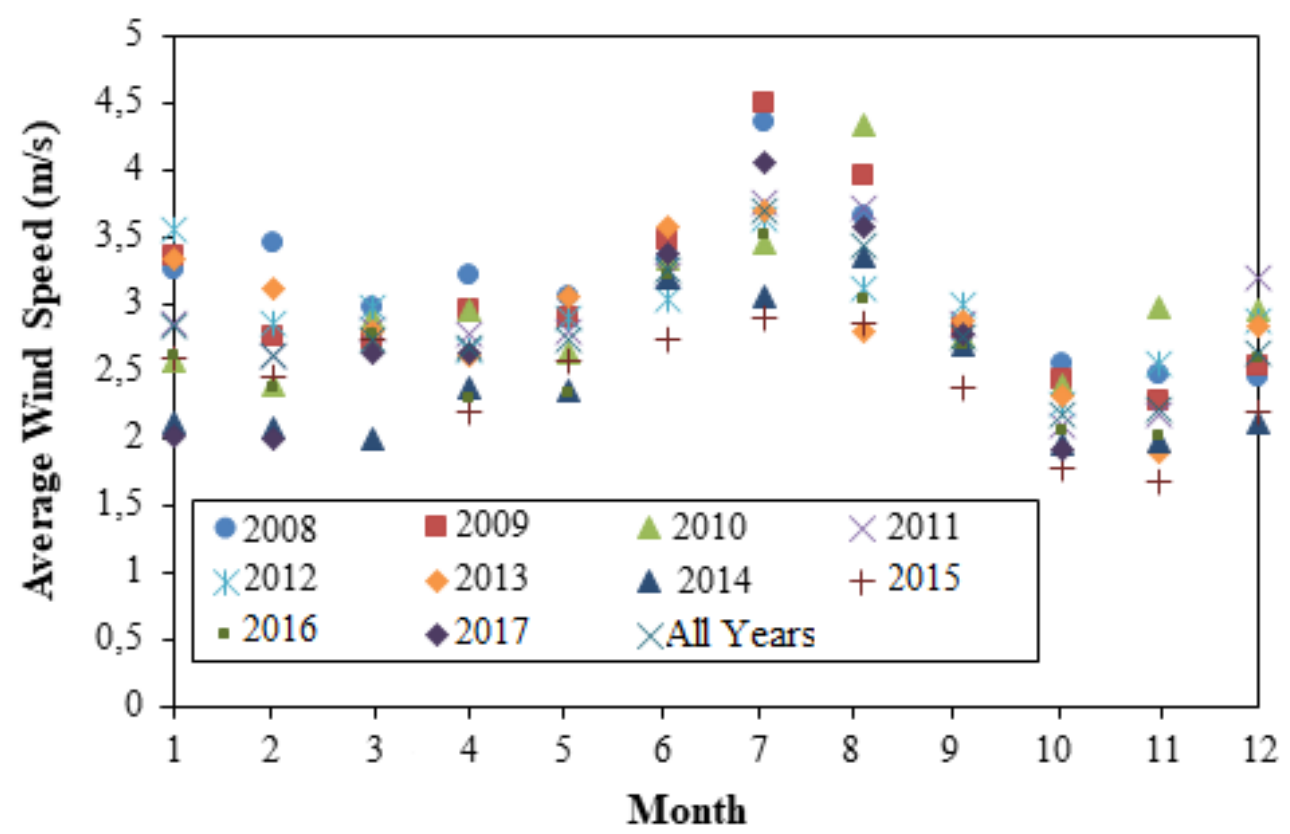

Figure 7. Exchange by months the average wind speed for Iskenderun province

According to Figure 6, the lowest wind speed was $1.53 \mathrm{~m} / \mathrm{s}$ in October of 2017 and highest wind speed was $3.09 \mathrm{~m} / \mathrm{s}$ in Jun of 2011. In Figure 7, the lowest wind speed was $1.68 \mathrm{~m} / \mathrm{s}$ in November of 2015 and highest wind speed was $4.5 \mathrm{~m} / \mathrm{s}$ in July of 2009 .

Annual wind power calculated for the selected Adıyaman and İskenderun from different regions of Turkey $\mathrm{P}_{\mathrm{w}}$ values for DT and MLP predictive models were obtained. Estimated $\mathrm{P}_{\mathrm{w}}$ values obtained with DT and MLP models are shown in Figures 8 and 9. In These figures, the $P_{w}$ values calculated with the Weibull cumulative distribution function are very similar to the predicted $\mathrm{P}_{\mathrm{w}}$ values with the DT and the MLP.

The properties of the network structures of the MLP algorithm are shown in Table 6. Three different models have been tried in MLP to be able to model with the least amount of errors. In these models, Feed forward back propagation (FFBP) network type, Tansig transfer functions, Levenberg-Marquardt (LM) algorithm were used. As a result, Model 3 was used according to the least RMSE error value in Table 6. 
Table 6. Network Structure Models of MLP

\begin{tabular}{lllllll}
\hline Model & Network & $\begin{array}{l}\text { Training } \\
\text { algorithm }\end{array}$ & Transfer function & $\begin{array}{l}\text { Number of layers } \\
\text { and neurons }\end{array}$ & Epochs & RMSE \\
\hline 1 & FFBP & LM & Tansig & $4-4-1$ & 110 & 1.25 \\
2 & FFBP & LM & Tansig & $5-5-1$ & 201 & 0.82 \\
3 & FFBP & LM & Tansig & $6-6-1$ & 141 & 0.54 \\
\hline
\end{tabular}

The error analysis values used to measure the accuracy of the DT and the MLP are given in Table 7. The error analysis values for the DT and the MLP are generally smaller than 1 for Adiyaman. In the predictive model made with the DT and the MLP for the $\mathrm{P}_{\mathrm{w}}$ values of Iskenderun, the error value is bigger than 1 . The DT algorithm used the M5P model tree for data modelling. The M5P algorithm used by the DT is a more advanced version of the M5 algorithm first discovered by Quinlan [33]. The most important advantage of DT is that the models created by using high dimensional and different character data have low error values. M5 model trees are used under the name of M5P in WEKA 3.8 software library.

Figures 10 and 11 show the structure of the M5P model tree to model the $\mathrm{P}_{\mathrm{w}}$ values. The DT algorithm randomly determined the rules and LM equations in these tree structures. The decision tree structure created by DT algorithm for $P_{w}$ values is shown in Figure 10. The $V_{\max }$ parameter forms the inner root of the tree. $\mathrm{P}_{\mathrm{w}}$ values are modeled according to decision rules based on $\mathrm{V}_{\max }$ values. The LM 1-3 parameters form the leaves of the tree. While modeling any parameter in the DT algorithm, decision rules are applied until the data is separated by decisions in the branches and reaches the LM values. In DT algorithm, rules and root data are determined randomly.

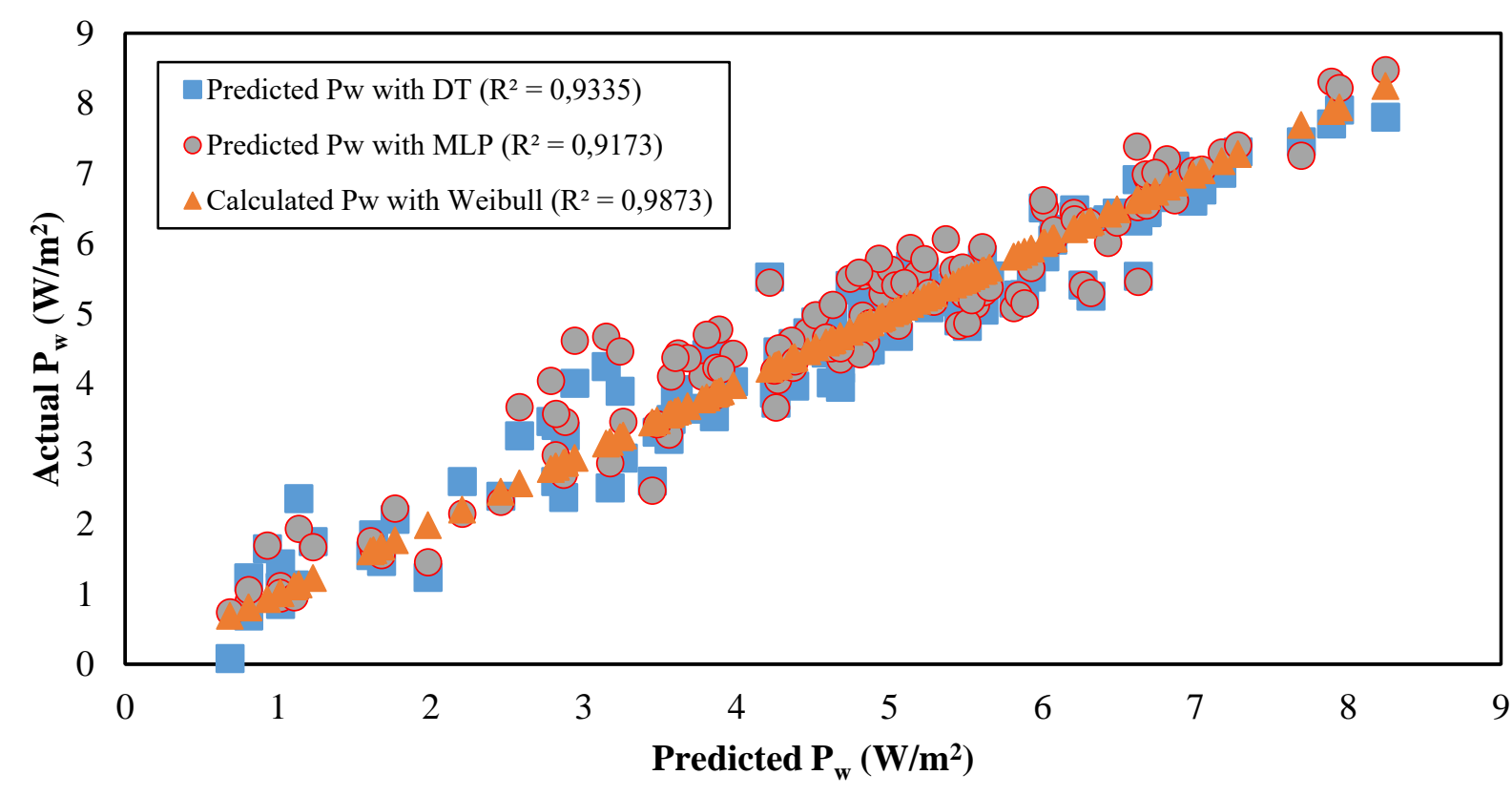

Figure 8. Experimental values and $P_{w}$ values estimated by DT and MLP models for Adiyaman 


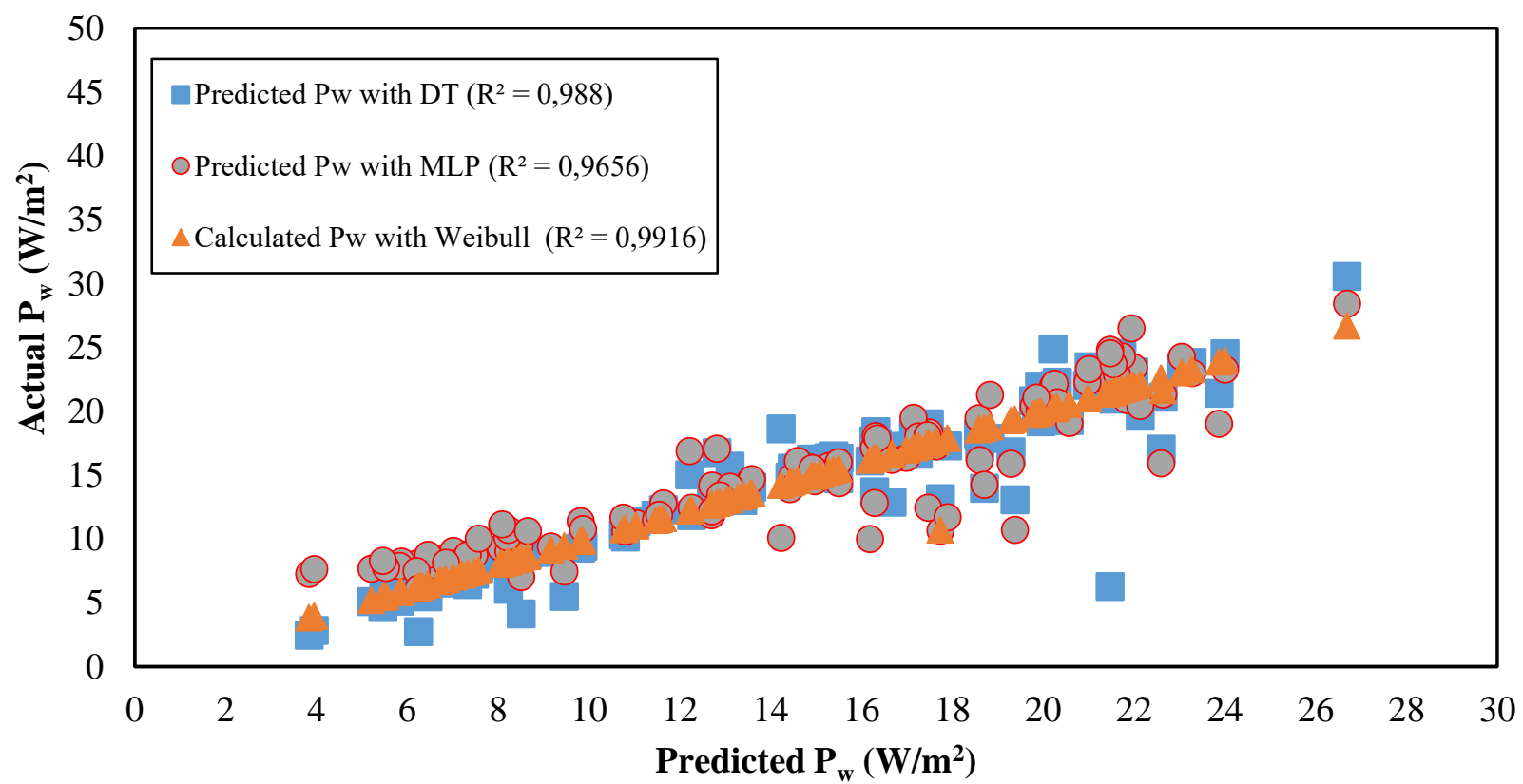

Figure 9. Experimental values and $P_{w}$ values estimated by DT and MLP models for Iskenderun

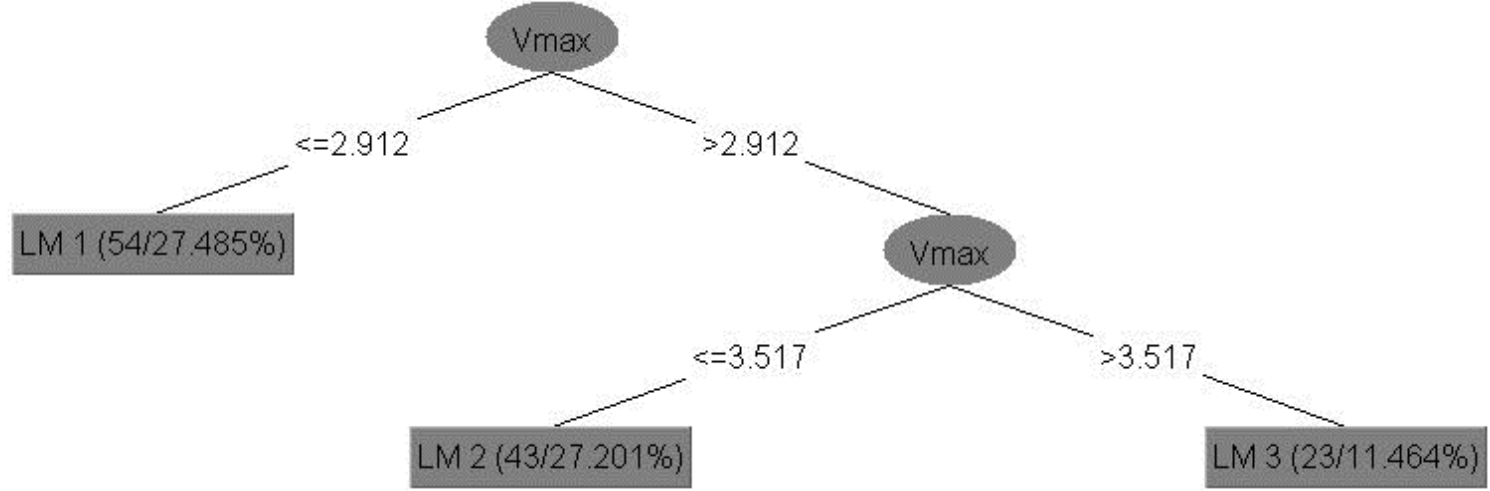

Figure 10. DT algorithm tree structure for the estimate of Adiyaman's Pw values

Linear models (LM) are used while creating the decision tree for the $\mathrm{P}_{\mathrm{w}}$ values model in the DT algorithm. These linear equations are given in Table 7.

Table 7. LM leaf linear equations of $P_{w}$ values of Adiyaman

\section{LM 1}

$P_{w}=0,3857 \cdot V_{\max }+1,351 \cdot V_{m}+1,6299 \cdot V_{\bmod }-2,2837$

\section{LM 2}

$P_{w}=0,6961 \cdot V_{\max }+0,7942 \cdot V_{m}+0,6518 \cdot V_{\bmod }+0,2835$

\section{LM 3}

$P_{w}=2,7513 \cdot V_{\max }+0,4048 \cdot V_{m}+0,4978 \cdot V_{\bmod }-5,5409$

In Figure 11, depending on the values of $\sigma$ (Sigma), $\mathrm{V}_{\mathrm{m}}$ and $\mathrm{c}$ in the decision tree, $\mathrm{P}_{\mathrm{w}}$ values are modelled according to the decision rules in the branches of the trees. In Figure 11, parameter $\sigma$ (Sigma) creates the root part of the tree, $V_{m}$ and $c$ values form the inner root. Parameters of LM 1-6 form the leaves of the tree. LM 1-6 linear models for İskenderun Pw values are given in Table 8. 


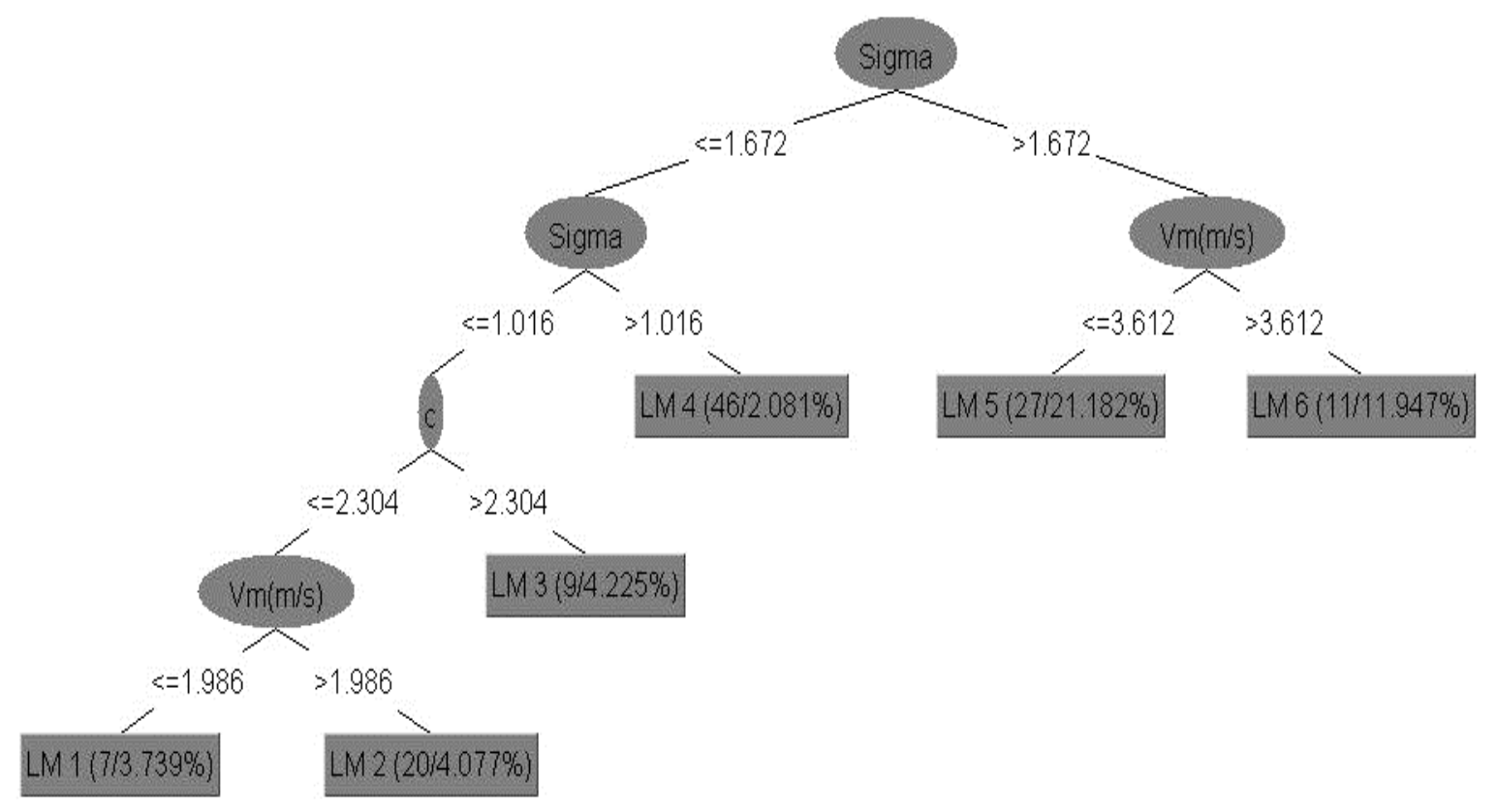

Figure 11. DT algorithm tree structure for the estimate of Iskenderun's Pw values

Table 8. LM leaf linear equations of $P_{w}$ values of Iskenderun

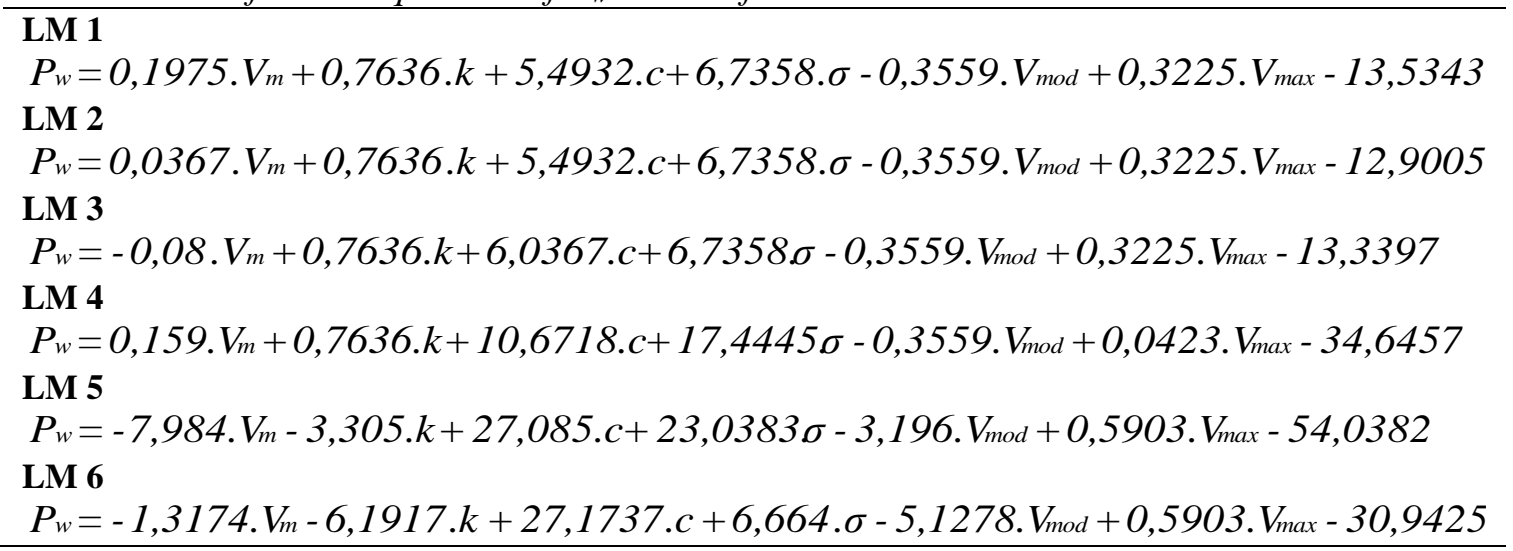

These linear equations produced for the M5P algorithm can also be used to calculate $\mathrm{P}_{\mathrm{w}}$ values for different models. Error analysis of DT and MLP used for estimating $\mathrm{P}_{\mathrm{w}}$ values are given in Table 9.

Table 9. Error analysis results of DT and MLP used for estimating $P_{w}$ values

\begin{tabular}{|c|c|c|c|c|c|}
\hline \multicolumn{6}{|c|}{ Error Analyses } \\
\hline \multicolumn{2}{|c|}{ Machine Learning Algorithms } & MAE & RMSE & RAE & RRSE \\
\hline \multirow{2}{*}{ 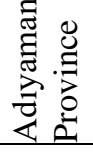 } & DT & 0.249 & 0.461 & 0.1 & 0.13 \\
\hline & MLP & 0.418 & 0.541 & 0.11 & 0.129 \\
\hline \multirow{2}{*}{ 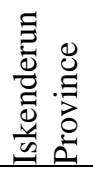 } & DT & 0.396 & 1.16 & 0.25 & 1.06 \\
\hline & MLP & 1.02 & 1.28 & 0.29 & 1.03 \\
\hline
\end{tabular}

There are many studies in the literature to model wind characteristics. In the studies conducted, generally wind speed and wind power values are modelled. The methods used in these models are mainly support vector regression (SVR), radial basis function (RBF), MLP, support vector machine (SVM), neighbours $(\mathrm{kNN})$ vector machine (LSSVM) and extreme learning machine (ELM). In the literature, the predictive model studies for wind characteristics are given in Table 10. The error analysis results of the models made 
for some wind features in Table 10 are generally higher than the error analysis results of wind energy modelling with MLP and DT algorithms in this study.

Table 10. Predictive models of wind properties in literature

\begin{tabular}{|c|c|c|c|c|}
\hline Predicted properties & Method & Error Analysis & $\begin{array}{l}\text { Error } \\
\text { Analysis } \\
\text { Result } \\
\end{array}$ & Reference \\
\hline Short term wind power & SVR & MAE & 0.118 & Zameer et al. ${ }^{[34]}$ \\
\hline Wind speed distribution & $\mathrm{RBF}$ & RMSE & 0.44 & Petković et al. ${ }^{[35]}$ \\
\hline Wind speed & MLP & RMSE & 1.6 & Liu et al. ${ }^{[36]}$ \\
\hline Short-term wind power & SVM & RMSE & 4.7 & Yuan et al. ${ }^{[37]}$ \\
\hline Wind power & $\mathrm{kNN}$ & RMSE & 0.43 & Yesilbudak et al. ${ }^{[38]}$ \\
\hline Wind power & MLP & MAE & 0.48 & Ouyang et al. ${ }^{[39]}$ \\
\hline Wind power & LSSVM & MAE & 0.25 & Yuan et al. ${ }^{[40]}$ \\
\hline Wind power & ELM & MAE & 4.07 & Ning et al. ${ }^{[41]}$ \\
\hline
\end{tabular}

\section{CONCLUSIONS}

In this study, wind energy density data of Adiyaman and İskenderun provinces were analysed based on the wind speed data measured in hourly intervals between 2008 and 2017 and a potential wind energy survey was conducted with the Weibull cumulative function. Using the Weibull cumulative function, the lowest wind speed of Adiyaman was calculated as $1.53 \mathrm{~m} / \mathrm{s}$ and the highest wind speed $3.09 \mathrm{~m} / \mathrm{s}$. At the same time, the lowest wind speed of Iskenderun was calculated as $1.68 \mathrm{~m} / \mathrm{s}$ and the highest wind speed was calculated as $4.5 \mathrm{~m} / \mathrm{s}$. Since the average speed is usually $3 \mathrm{~m} / \mathrm{s}$ higher per day and per month, it is determined that electricity production from wind energy is suitable in İskenderun province. Adiyaman province is not suitable for electricity generation from wind energy [42]. It has been found that monthly average power densities less than $100 \mathrm{~W} / \mathrm{m}^{2}$ can be used in applications where direct support to the network by wind energy systems is not possible, where there is no grid access or where low power density is required in rural areas. A predictive models were established using machine learning algorithms for the $\mathrm{P}_{\mathrm{w}}$ values. The DT and the MLP algorithms were used for predictive models. The best estimate was made by the DT algorithm for Adiyaman province with the lowest error rates (0.249 MAE). As a result, in this study, $\mathrm{P}_{\mathrm{w}}$ values were obtained by using 10-year wind speed data with the help of the Weibull distribution function. The $\mathrm{P}_{\mathrm{w}}$ values obtained were modelled by machine learning algorithms DT and MLP. Thus, $\mathrm{P}_{\mathrm{w}}$ values were modelled with both mathematically and machine algorithms. It is expected that the wind power estimation model will be used as an example for wind power studies for different regions. Using the network input parameters selected for the machine learning algorithms obtained in this study, wind energy density values in different regions can be estimated. Thus, the wind power potentials of different regions can be determined. Different computational intelligence methods or more data sets can be used to create predictive models with less error rates.

\section{CONFLICTS OF INTEREST}

No conflict of interest was declared by the authors.

\section{REFERENCES}

[1] Sahin, A. D. A., "Review of Research and Development of Wind Energy in Turkey", Clean-Soil, Air, Water, 36: 734-742, (2008). 
[2] Babu, S., Loganathan, A., Varravasundaram, I., "Optimizing Electrical Generators of Wind Energy Conversion System for Efficient Power Extraction", Gazi University Journal of Science, 31(4): 1141-1154, (2018).

[3] Wind Energy potential in Europe, https://windeurope.org/ (2020). Access Date: 14.09.2020

[4] Mutlu, Ö., Akpınar, S. E., Balıkçı, A., "Power Quality Analysis of Wind Farm Connected to Alaçatı Substation in Turkey", Renewable Energy, 34(5): 1312-1318, (2009).

[5] Jaramillo, O. A., Borja, M. A., "Wind speed analysis in La Ventosa, Mexico: a bimodal probability distribution case", Renewable Energy, 29: 1613-1630, (2004).

[6] Incecik, S., Erdogmus, F., "An Investigation of the Wind Power Potential on the Western Coast of Anatolia", Renewable Energy, 6: 863-865, (1995).

[7] Kose, R., Ozgur, M. A., Erbas, O., Tugcu, A., "The Analysis of Wind Data and Wind Energy Potential in Kutahya, Turkey”, Renewable and Sustainable Energy Reviews, 8: 277-288, (2004).

[8] Akpınar, E. K., Akpınar, S., "Determination of the Wind Energy Potential for Maden-Elazig, Turkey”, Energy Conversion and Management, 45: 2901-2914, (2004).

[9] Dorvlo, A. S., "Estimating wind speed distribution", Energy Conversion and Management, 43(17): 2311-2318, (2002).

[10] Efe-eyefia, E., Thomas, J., Zelibe, S., "Theoretical Analysis of the Weibull Alpha Power Inverted Exponential Distribution: Properties and Applications", Gazi University Journal of Science, 33 (1): 265-277, (2020).

[11] Carta, J. A., Ramirez, P., Bueno, C., "A joint probability density function of wind speed and direction for wind energy analysis", Energy Conversion and Management, 49(6): 1309-1320, (2008).

[12] Shu, Z. R., Li, Q. S., Chan, P. W., "Investigation of offshore wind energy potential in Hong Kong based on Weibull distribution function", Applied Energy, 156: 362-373, (2015).

[13] Usta, I., "An innovative estimation method regarding Weibull parameters for wind energy applications", Energy, 106: 301-314, (2016).

[14] Mohammadi, K., Alavi, O., Mostafaeipour, A., Goudarzi, N., Jalilvand, M., "Assessing different parameters estimation methods of Weibull distribution to compute wind power density", Energy Conversion and Management, 108: 322-335, (2016).

[15] Ramírez, P., Carta, J. A., "Influence of the data sampling interval in the estimation of the parameters of the Weibull wind speed probability density distribution: a case study", Energy Conversion and Management, 46(15-16): 2419-2438, (2005).

[16] Akdağ, S. A., Dinler, A., "A new method to estimate Weibull parameters for wind energy applications", Energy Conversion and Management, 50(7): 1761-1766, (2009).

[17] Yu, C., Li, Y., Bao, Y., Tang, H., Zhai, G., "A novel framework for wind speed prediction based on recurrent neural networks and support vector machine", Energy Conversion and Management, 178: 137-145, (2018). 
[18] Cliff, W. C., "The Effect of generalized wind characteristics on annual power estimates from wind turbine generators", Washington Battele Pacific: Northwest Laboratory, (1977).

[19] Çelik, A. N., "A Statistical analysis of wind power density based on the Weibull and Rayleigh models at Southern Region of Turkey”, Renewable Energy, 29: 593-604, (2004).

[20] Chang, T. P., "Performance comparison of six numerical methods in estimating Weibull parameters for wind energy application”, Apply Energy, 88: 272-282, (2011).

[21] Erdem, O., Kesen, S., "Estimation of Turkey's Natural Gas Consumption by Machine Learning Techniques", Gazi University Journal of Science, 33(1): 120-133, (2020).

[22] Çerçi, K. N., Hürdoğan, E., "Comparative study of multiple linear regression (MLR) and artificial neural network (ANN) techniques to model a solid desiccant wheel", International Communications in Heat and Mass Transfer, 116: 104713, (2020).

[23] Reikard, G., "Regime-switching models and multiple causal factors in forecasting wind speed", Wind Energy", 13(5): 407-418, (2010).

[24] Guler, G., Hardalac, F., Arıcioglu, A., "Examination of Electric Field Effects on Lipid Peroxidation and Antioxidant Enzymes by Using Multilayer Perceptron Neural Network", Gazi University Journal of Science, 24(2): 385-386, (2011).

[25] Çerçi, K. N., Daş, M., "Modeling of Heat Transfer Coefficient in Solar Greenhouse Type Drying Systems", Sustainability, 11(18): 5127, (2019).

[26] Ellis, N., Davy, R., Troccoli, A., "Predicting wind power variability events using different statistical methods driven by regional atmospheric model output", Wind Energy, 18(9): 16111628, (2015).

[27] Ayaz, Y., Kocamaz, A. F., Karakoç, M.B., "Modelling of compressive strength and UPV of highvolume mineral-admixtured concrete using rule-based M5 rule and tree model M5P classifiers", Construction and Building Materials, 94: 235-240, (2015).

[28] Behnood, A., Behnood, V., Gharehveran, M. M, Alyamac, K. E., "Prediction of the compressive strength of normal and high-performance concretes using M5P model tree algorithm", Construction and Building Materials, 142: 199-207, (2017).

[29] Alic, E., Das, M., Kaska, O., "Heat Flux Estimation at Pool Boiling Processes with Computational Intelligence Methods", Processes, 7(5): 293, (2019).

[30] Aggarwal, G., Sabharwal, S., Nagpal, S., "Theoretical and Empirical Validation of Coupling Metrics for Object-Oriented Data Warehouse Design", Arabian Journal for Science and Engineering, 43(2): 675-691, (2018).

[31] Wang, Y., Witten I. H., "Induction of model trees for predicting continuous classes, in: Proc of the Poster Papers of the European Conference on Machine Learning", University of Economics, Faculty of Informatics and Statistics: Prague, (1997).

[32] Hourly wind speed data. https://www.mgm.gov.tr/ (2020) Access Date: 16 September 2020

[33] Quinlan, J. R., "Learning with continuous classes, in: Proceedings of the Australian Joint Conference on Artificial Intelligence", World Scientific: Singapore, (1992). 
[34] Zameer, A., Khan, A., Javed, S. G., "Machine Learning based short-term wind power prediction using a hybrid learning model", Computers \& Electrical Engineering, 45: 122-133, (2015).

[35] Petkovic, D., Shamshirband, S., Anuar, N. B., Saboohi, H., Wahab, A. W. A., Protic, M., Zalnezhad, E., Mirhashemi, S.M.A., "An appraisal of wind speed distribution prediction by soft computing methodologies: a comparative study", Energy conversion and Management, 84: 133$139,(2014)$.

[36] Liu, H., Tian, H.Q., Li, Y.F., "Four wind speed multi-step forecasting models using extreme learning machines and signal decomposing algorithms", Energy conversion and management, 100: 16-22, (2015).

[37] Yuan, X., Chen, C., Yuan, Y., Huang, Y., Tan, Q., "Short-term wind power prediction based on LSSVM-GSA model”, Energy Conversion and Management, 101: 393-401, (2015).

[38] Yesilbudak, M., Sagiroglu, S., Colak, I., "A novel implementation of kNN classifier based on multi-tupled meteorological input data for wind power prediction", Energy Conversion and Management, 135: 434-444, (2017).

[39] Ouyang, T., Zha, X., Qin L., “A combined multivariate model for wind power prediction”, Energy Conversion and Management, 144; 361-373, (2017).

[40] Yuan, X., Tan, Q., Lei, X., Yuan, Y., Wu, X., "Wind power prediction using hybrid autoregressive fractionally integrated moving average and least square support vector machine", Energy, 129: 122-137, (2017).

[41] Li, N., He, F. and Ma, W., "Wind Power Prediction Based on Extreme Learning Machine with Kernel Mean p-Power Error Loss", Energies, 12(4): 673, (2019).

[42] Daş, M., Balpetek, N., Akpınar, E. K., Akpınar, S., "Türkiye'de bulunan farklı illerin rüzgâr enerjisi potansiyelinin incelenmesi ve sonuçların destek vektör makinesi regresyon ile tahminsel modelinin oluşturulması", Journal of the Faculty of Engineering and Architecture of Gazi University, 34(4): 2203-2213, (2019). 